\title{
Espaçamento entre linhas na produtividade de biomassa e de grãos em genótipos de milheto pérola
}

\section{Space between the lines in the productivity of biomass and grains in genotypes of pearl millet}

\author{
Rafael Priesnitz ${ }^{1}$; Antonio Carlos Torres da Costa ${ }^{2 *}$; Paulo Evandro Jandrey ${ }^{3}$; \\ Jean Roger da Silva Fréż; José Barbosa Duarte Júnior²; Paulo Sérgio Rabello de \\ Oliveira $^{2}$
}

Resumo

O objetivo deste trabalho foi avaliar a influência do espaçamento entre linhas no rendimento de biomassa e de grãos de milheto pérola. O experimento foi instalado na Fazenda Experimental da Unioeste, situada na Linha Guará, município de Marechal Cândido Rondon - PR. O delineamento experimental utilizado foi o de blocos ao acaso, em esquema fatorial $2 \times 4$, com quatro repetições. Nos tratamentos utilizou-se de dois genótipos (Comum e IPA-BULK 1), conduzidos em quatro espaçamentos (20, 40, 60 e 80cm) em parcelas de $12 \mathrm{~m}^{2}$. Utilizou-se como densidade de semeadura $25 \mathrm{~kg} \mathrm{ha}^{-1}$ de sementes para todos os tratamentos. A semeadura foi realizada manualmente no dia 10 de outubro de 2008. Avaliou-se a produtividade de biomassa e de grãos, sendo que o espaçamento influenciou de forma significativa na produção de biomassa. Observou-se que a produção de biomassa decresceu em função do aumento no espaçamento entre linhas. O espaçamento de $20 \mathrm{~cm}$ entre linhas foi o que apresentou, em média, maior produção de massa verde e massa seca no estádio de grão pastoso, com 50,84 ton ha ${ }^{-1}$ e 17,60 ton ha ${ }^{-1}$, respectivamente. Houve interação significativa entre os fatores cultivar e espaçamento para a produção de massa seca na maturação fisiológica e para a produção de grãos. De maneira geral, as cultivares apresentaram elevado rendimento de biomassa e de grãos, podendo desta forma serem cultivadas na região de Marechal Cândido Rondon - PR, sendo uma importante alternativa para a cobertura do solo no sistema plantio direto e também como fonte de alimentação de animais.

Palavras-chave: Pennisetum glaucum. Espaçamento entre linhas. Biomassa.

\begin{abstract}
The objective of this study was to evaluate the influence of spacing between lines in yeld of biomass and grain cultivars in common and IPA-BULK 1 pearl millet. The experiment was installed at the Experimental Farm of Unioeste, located on Guará Line, Marechal Cândido Rondon - PR city. The experimental design was randomized blocks in factorial scheme $2 \times 4$, with four replications. In the treatments were used two genotypes (Usual IPA and BULK-1), conducted at four spacings $(20,40$, 60 e $80 \mathrm{~cm}$ ) in plots of $12 \mathrm{~m}^{2}$. It was used as seeding rate of $25 \mathrm{~kg} \mathrm{ha}^{-1}$ seeds for all treatments. Sowing was done manually on October 10, 2008. We evaluated the productivity of biomass and grain, and the
\end{abstract}

\footnotetext{
${ }^{1}$ Eng $^{\mathrm{o}}$. Agr ${ }^{\circ}$., Pós-graduando do Programa de Pós-Graduação em Agronomia, PPGA. Centro de Ciências Agrárias, CCA. Universidade Estadual do Oeste do Paraná. UNIOESTE. Campus de Marechal Cândido Rondon. E-mail: rafaelpagronomo@ hotmail.com

2 Eng ${ }^{\mathrm{O}}$ Agr ${ }^{\circ}$., D.Sc., Prof. Adjunto, Centro de Ciências Agrárias. PPGA/UNIOESTE. E-mail: torres_antoniocarlos@yahoo.com.br; bduarte7@yahoo.com.br; rabello.oliveira@hotmail.com

3 Discente de Graduação do Curso de Agronomia. Centro de Ciências Agrárias. UNIOESTE. E-mail: paulo_jandreypejota@ hotmail.com; jean_frez18@hotmail.com

* Autor para correspondência
} 
spacing significantly influenced the production of biomass. It was observed that the biomass decreased with increasing the spacing between lines. The spacing of $20 \mathrm{~cm}$ between rows was the, on average, increased production of green mass and dry mass at the stage of grain paste with 50.84 ton ha ${ }^{-1}$ and 17.60 ton ha $\mathrm{a}^{-1}$ respectively. There was a significant interaction between the factors cultivar and spacing for the production of dry matter in the physiological maturity and grain production. In general, the cultivars has high yield of biomass and grain, so it can be grown in the region of Marechal Cândido Rondon - PR, it is an important alternative for the soil cover in tillage system and also as the power source of animals feeding.

Key words: Pennisetum glaucum. Row spacing. Biomass.

\section{Introdução}

A cultura do milheto pérola (Pennisetum glaucum L.) é importante como fonte de pasto ou forragem de inverno em regiões e épocas com pouca disponibilidade hídrica, e em menor escala, como fonte de grãos utilizáveis em formulações de rações para animais (LANDERS, 1994; CALEGARI; PEÑALVA, 1994), pois apresenta excelente valor nutritivo (até $24 \%$ de proteína bruta quando em pastejo), boa palatabilidade e digestibilidade $(60 \%$ a 78\%) em pastejo, sendo atóxica aos animais em qualquer estádio vegetativo. Quando utilizado sob pastejo, com animais de recria pode proporcionar ganhos de até $600 \mathrm{~kg} \mathrm{ha}^{-1}$ de peso vivo, ou $20 @$ ha $^{-1}$ de carne em 150 dias de pastejo, equivalente a ganhos médios diários de $950 \mathrm{~g}^{\text {animal }}{ }^{-1}$, com 4,2 animais ha-1 (KICHEL; MIRANDA, 2000).

Também é uma excelente opção para a produção de palha para cobertura de solos no sistema de plantio direto tanto no Cerrado como também para a região Sul, além de ser utilizado para amenizar os efeitos da compactação dos solos, pois possui um sistema radicular vigoroso, que deixam canais que propiciam condições ao desenvolvimento de raízes da cultura subseqüente (WANG; HESKETH; WOOLLEY, 1986). Segundo Fiorin (1999), espécies que possuam sistema radicular profundo e ramificado podem retirar nutrientes de camadas subsuperficiais, e liberá-los gradualmente nas camadas superficiais, durante o processo de decomposição, contribuindo para manter o equilíbrio dos nutrientes no solo e aumentar a sua fertilidade, além de permitir melhor utilização dos insumos agrícolas.

Em trabalho conduzido por Salton, Pitol e Erbes (1993), estudando espécies de cobertura para o sistema de plantio direto, verificaram que o milheto foi a cultura que mais produziu massa, atingindo 5,5 e $9 \mathrm{t} \mathrm{ha}^{-1}$, quando colhida aos 57 e 72 dias após a semeadura, respectivamente.

Geraldo et al. (2002), observaram que na maturação fisiológica do milheto, houve um decréscimo no teor de $\mathrm{N}$ nas folhas baixeiras, devido a remobilização para folhas superiores e para o grão, contudo, as folhas medianas e apicais continuaram a ter um alto teor de $\mathrm{N}$, mesmo na maturação do grão, o que caracteriza a capacidade da planta manter uma alta atividade fotossintética no final de ciclo, concluindo assim que a massa seca para forragem ou silagem, ainda com alto teor de $\mathrm{N}$ nas folhas, pode ser obtida mediante a colheita do milheto no estádio de maturação fisiológica, e que ainda apresenta a vantagem da produção de grãos.

Dependendo da finalidade, o milheto pode ser cultivado em espaçamentos que variam entre 15 e 80 $\mathrm{cm}$ entre linhas, sendo que nos espaçamentos mais estreitos a produção de matéria seca geralmente se apresenta maior, porém em contrapartida a maior competição entre plantas nesses espaçamentos pode gerar um maior grau de acamamento e uma menor produção de grãos por panícula. Assim o espaçamento deve ser definido em função da finalidade do cultivo, para cobertura do solo com aproximadamente $15 \mathrm{~cm}$ entre linhas, produção de forragem com aproximadamente $40 \mathrm{~cm}$, ou produção de grãos entre 70 e $80 \mathrm{~cm}$ (PEREIRA FILHO et al., 2003; COSTA et al., 2005).

O presente trabalho teve por objetivo estudar a relação do espaçamento entre linhas com o rendimento de biomassa verde e seca e produtividade de grãos em duas cultivares de milheto pérola. 


\section{Material e Métodos}

O experimento foi conduzido na fazenda experimental Dr. Antônio Carlos dos Santos Pessoa, pertencente ao Núcleo de Estações Experimentais da Universidade Estadual do Oeste do Paraná, situada na Linha Guará no município de Marechal Cândido Rondon - PR. A média mensal de temperatura e de precipitação pluviométrica ocorridas durante a condução do experimento foi de $24,07^{\circ} \mathrm{C}$ e 123,33 $\mathrm{mm}$, respectivamente.

O local onde realizou-se o experimento está localizado na latitude $24^{\circ} 31^{\prime} 59,49^{\prime \prime} \mathrm{S}$ e longitude $54^{\circ} 01^{\prime} 13,67^{\prime}$ W, e com altitude média de 420 metros, cujo solo é um LATOSSOLO VERMELHO eutroférrico de textura muito argilosa (EMPRESA BRASILEIRA DE PESQUISA AGROPECUÁRIA - EMBRAPA, 1999), cujas características químicas na camada de 0 a $20 \mathrm{~cm}$ de profundidade foram determinadas antes da instalação do experimento apresentavam os seguintes valores: $42,86 \mathrm{mg} \mathrm{dm}^{-3}$ de P, 28,71 $\mathrm{g} \mathrm{dm}^{-3}$ de M.O., 0,26, 5,46, 2,22, 0,20 e 4,99 cmolc $\mathrm{dm}^{-3}$ de $\mathrm{K}, \mathrm{Ca}, \mathrm{Mg}, \mathrm{Al} \mathrm{e} \mathrm{H}^{+}+\mathrm{Al}$, respectivamente, $\mathrm{pH}\left(\mathrm{CaCl}_{2}\right) 5,03$, e $61,41 \%$ de saturação por bases ( $\mathrm{V} \%)$.

O delineamento experimental utilizado foi $\mathrm{o}$ de blocos ao acaso em esquema fatorial $2 \times 4$, com quatro repetições, totalizando 8 tratamentos. Os tratamentos foram compostos por duas cultivares (cv. Comum e cv. IPA-BULK 1), conduzidas em quatro espaçamentos (20, 40, 60 e $80 \mathrm{~cm}$ entre linhas), em parcelas de $12 \mathrm{~m}^{2}$. Cada parcela experimental teve $2,5 \mathrm{~m}$ de largura por $4,8 \mathrm{~m}$ de comprimento. $\mathrm{O}$ número de linhas na parcela variou de acordo com o espaçamento adotado. Foram consideradas como bordaduras, as linhas externas de cada parcela e 0,5 $\mathrm{m}$ da extremidade da parcela.

A semeadura do milheto foi realizada manualmente no dia 10 de outubro de 2008, utilizando-se a densidade de $25 \mathrm{Kg} \mathrm{ha}^{-1}$ de sementes. Devido às boas condições de umidade do solo, não foi necessário efetuar irrigação por ocasião da semeadura. Não foi realizada calagem e adubação.
Não foi necessário utilizar medidas para controle de pragas e doenças e também não houve a necessidade de controle de plantas daninhas.

Para determinar-se a produção de biomassa, visando o uso do milheto como forragem e silagem, foram coletadas no estádio de grão pastoso (E8), em uma área central de 1,0 $\mathrm{m}^{2}$ de cada parcela, uma amostra de toda a parte aérea. E para determinar-se a produção de biomassa, visando o uso do milheto como forragem e como palhada para a cobertura do solo no sistema de plantio direto, foram coletadas no estádio de maturação fisiológica (E9), em uma área central de 1,0 $\mathrm{m}^{2}$ de cada parcela, uma amostra de toda a parte aérea.

Em ambos estádios, procedeu-se a pesagem da amostra, obtendo assim, a produtividade de massa verde. E para determinar a massa seca, o material foi levado para estufa de circulação de ar a $65{ }^{\circ} \mathrm{C}$ por sete dias, até atingir massa constante, e após isto, obteve-se sua massa seca. Os resultados foram extrapolados para produção em $\mathrm{t}$ ha $^{-1}$ de massa verde e massa seca.

Das plantas coletadas na área de $1,0 \mathrm{~m}^{2}$ de cada parcela, no E9, onde foi determinada a produção de biomassa, nestas mesmas plantas, também foram determinados, os caracteres número de panículas e o comprimento das mesmas, bem como a produtividade de grãos em $\mathrm{kg} \mathrm{ha}^{-1}$.

A análise de variância foi feita seguindo o modelo de blocos ao acaso, em esquema fatorial e para analisar o efeito dos espaçamentos utilizados foi realizada a análise de regressão. A análise estatística, incluindo estudo de regressão, foi realizada utilizando o programa SAEG.

\section{Resultados e Discussão}

Os resultados apresentados na (Tabela 1) referente ao resumo da análise de variância das características avaliadas nas duas cultivares de milheto submetidas a diferentes espaçamentos entre linhas, demonstram que houve interação significativa entre os fatores 
avaliados apenas nas características biomassa seca da planta no estádio de maturação fisiológica e produtividade de grãos. Analisando separadamente cultivar e espaçamento, verifica-se que pela análise de variância os espaçamentos estudados diferiram entre si em todas as variáveis estudadas, já entre cultivares não houve diferenças estatísticas para nenhuma das características avaliadas. Estes resultados das cultivares também podem ser observados na (Tabela 2) onde estão apresentados os valores médios das características avaliadas.

Tabela 1. Resumo da análise de variância da biomassa verde e biomassa seca no estágio de grão pastoso (BVGP e BSGP), biomassa verde e biomassa seca no estádio de maturação fisiológica (MVF e MSF), comprimento médio das panículas (CPA), produção de grãos (PG), e número de panículas (NPA), avaliadas em duas cultivares de milheto pérola em diferentes espaçamentos. Marechal Cândido Rondon-PR. 2008.

\begin{tabular}{llllclcc}
\hline FV & & \multicolumn{5}{c}{ Quadrado Médio } \\
& BVGP & BSGP & MVF & MSF & CPA & PG & NPA \\
\hline Bloco & $129.52^{\text {ns }}$ & $3.59^{\text {ns }}$ & $44.69^{\text {ns }}$ & $3.83^{\text {ns }}$ & $0.11^{\text {ns }}$ & $216862.1^{\text {ns }}$ & $1692.68^{\text {ns }}$ \\
Cultivar & $8.20 \mathrm{~ns}$ & $2.26^{\text {ns }}$ & $8.71^{\text {ns }}$ & $4.08^{\text {ns }}$ & $0.78^{\text {ns }}$ & $93.59^{\text {ns }}$ & $4974.28^{\text {ns }}$ \\
Espaçamento & $577.21^{* *}$ & $98.07^{* *}$ & $837.16^{* *}$ & $121.45^{* *}$ & $6.56^{* *}$ & $1437275 .^{* *}$ & $73330.4^{* *}$ \\
Cul x Esp & $94.20^{\text {ns }}$ & $7.28^{\text {ns }}$ & $137.94^{\text {ns }}$ & $23.20^{* *}$ & $1.77^{\text {ns }}$ & $1079165 .^{* *}$ & $2604.14^{\text {ns }}$ \\
Resíduo & 49.81 & 4.57 & 51.23 & 4.57 & 0.77 & 121207.5 & 1428.43 \\
CV\% & 17.67 & 16.63 & 16.40 & 14.53 & 4.25 & 29.22 & 19.80 \\
\hline
\end{tabular}

${ }^{\mathrm{ns}}$ não significativo pelo teste $\mathrm{F}$; * significativo a $5 \%$ de probabilidade pelo teste $\mathrm{F}$; ** significativo a $1 \%$ de probabilidade pelo teste F.

Tabela 2. Média da biomassa verde e biomassa seca no estádio de grão pastoso (BVGP e BSGP), biomassa verde na maturação fisiológica (MVF), comprimento médio das panículas (CPA), e número de panículas (NPA), em duas cultivares de milheto pérola. Marechal Cândido Rondon-PR. 2008.

\begin{tabular}{|c|c|c|c|c|c|}
\hline Genótipo & $\operatorname{BVGP}\left(\mathrm{t} \mathrm{ha}^{-1}\right)$ & $\operatorname{BSGP}\left(\mathrm{t} \mathrm{ha}^{-1}\right)$ & MVF $\left(\mathrm{t} \mathrm{ha}^{-1}\right)$ & CPA $(\mathrm{cm})$ & $\operatorname{NPA}\left(\mathrm{m}^{2}\right)$ \\
\hline Comum & 39,42 & 12,60 & 44,16 & 20,48 & 203,28 \\
\hline IPA-BULK 1 & 40,44 & 13,13 & 43,12 & 20,80 & 178,34 \\
\hline Média & 39,93 & 12,86 & 43,64 & 20,64 & 190,81 \\
\hline $\mathrm{CV} \%$ & 17,67 & 16,63 & 16,40 & 4,25 & 19,81 \\
\hline
\end{tabular}

A diferença entre cultivares não foi expressiva sendo que a cultivar IPA-BULK 1 apresentou $1,02 \mathrm{t} \mathrm{ha}^{-1}$ de biomassa verde e de $0,53 \mathrm{tha}^{-1} \mathrm{de}$ biomassa seca a mais que a cultivar comum quando as plantas de milheto se encontravam no estádio de grão pastoso. Já no estádio de maturação esta apresentou maior valor apenas no comprimento da panícula. Já para as características avaliadas no estádio de maturação, biomassa verde e número de panículas por metro quadrado a cultivar Comum apresentou valores de 1,04 tha $\mathrm{ha}^{-1}$ e 24,94 panículas $\mathrm{m}^{-2}$, respectivamente. Esses dados demonstraram que apesar de não haver diferença significativa, a cultivar IPA-BULK 1 apresenta leve aumento de biomassa na fase de grãos pastosos, fase esta em que se utiliza o milheto como forragem. Estes resultados apontam que para esta região em questão, espera-se que independente das cultivares estudadas haja uma diferença não significativa na produção de biomassa e de grãos.

De acordo com Maggi (1994), o pastejo direto desta forrageira, proporcionou ganho de peso dos bovinos em até $1,3 \mathrm{~kg}$ dia- ${ }^{1}$. Entretanto, com o manejo adequado do milheto, pode-se obter até $7 \mathrm{~kg} \mathrm{ha}^{-1}$ dia $^{-1}$ de ganho de peso vivo (MORAES; MARASCHIN,1988). Esses autores, concluíram 
que esta cultura apresenta-se como uma alternativa interessante que pode integrar a pecuária e a agricultura, devido ao seu elevado potencial de produção de biomassa, como constatado neste estudo.

Quando o corte do milheto é feito nos estádios iniciais de desenvolvimento, a silagem tem se mostrado de baixa qualidade, devido ao menor teor de massa seca (BONAMIGO, 1999). Por isto, o corte para silagem deve ser realizado quando os grãos estiverem passando da fase de grão leitoso para grão pastoso (CALEGARI; PEÑALVA, 1994). A silagem de milheto neste estádio iguala-se em digestibilidade a silagem de milho, porém tem níveis mais altos de proteína bruta e maior produção de massa seca que o milho (NETTO, 1998).

$\mathrm{Na}$ (Figura 1) estão apresentadas as curvas ajustadas para a biomassa verde e seca no estádio de grãos pastosos em relação aos espaçamentos estudados (20, 40, 60 e $80 \mathrm{~cm})$. Para a biomassa verde (Figura 1A) equação apresentou ajuste linear decrescente com coeficiente de correlação " $r$ " de 0,94 significativa com $p<0,005$. A equação demonstra que para cada aumento de espaçamento a uma diminuição estimada de $0,3183 \mathrm{t} \mathrm{ha}^{-1}$ de biomassa verde. Para o espaçamento de 0,20 foi observado um valor de biomassa verde de 50,84 $\mathrm{t} \mathrm{ha}^{-1}$, enquanto que no espaçamento de 0,80 foi de 32,43 t ha-1, uma diminuição de $18,41 \mathrm{t} \mathrm{ha}^{-1}$ de biomassa fresca quando se passa do espaçamento de 0,20 para 0,80, ou seja 0,2301 t ha-1 a cada diminuição do espaçamento. Dados semelhantes foram obtidos por Silva et al. (2004) que verificaram em seus estudos uma diminuição da produção de biomassa verde a medida em que se aumentou o espaçamento entre linhas e, que a maior produção foi obtida com espaçamento de 0,20 m. Já Pawel et al. (1995) verificaram maior produção de biomassa verde quando utilizaram o espaçamento de $0,15 \mathrm{~m}$, entretanto observaram a mesma tendência observada neste estudo, onde com o aumento do espaçamento há um declínio da produção.
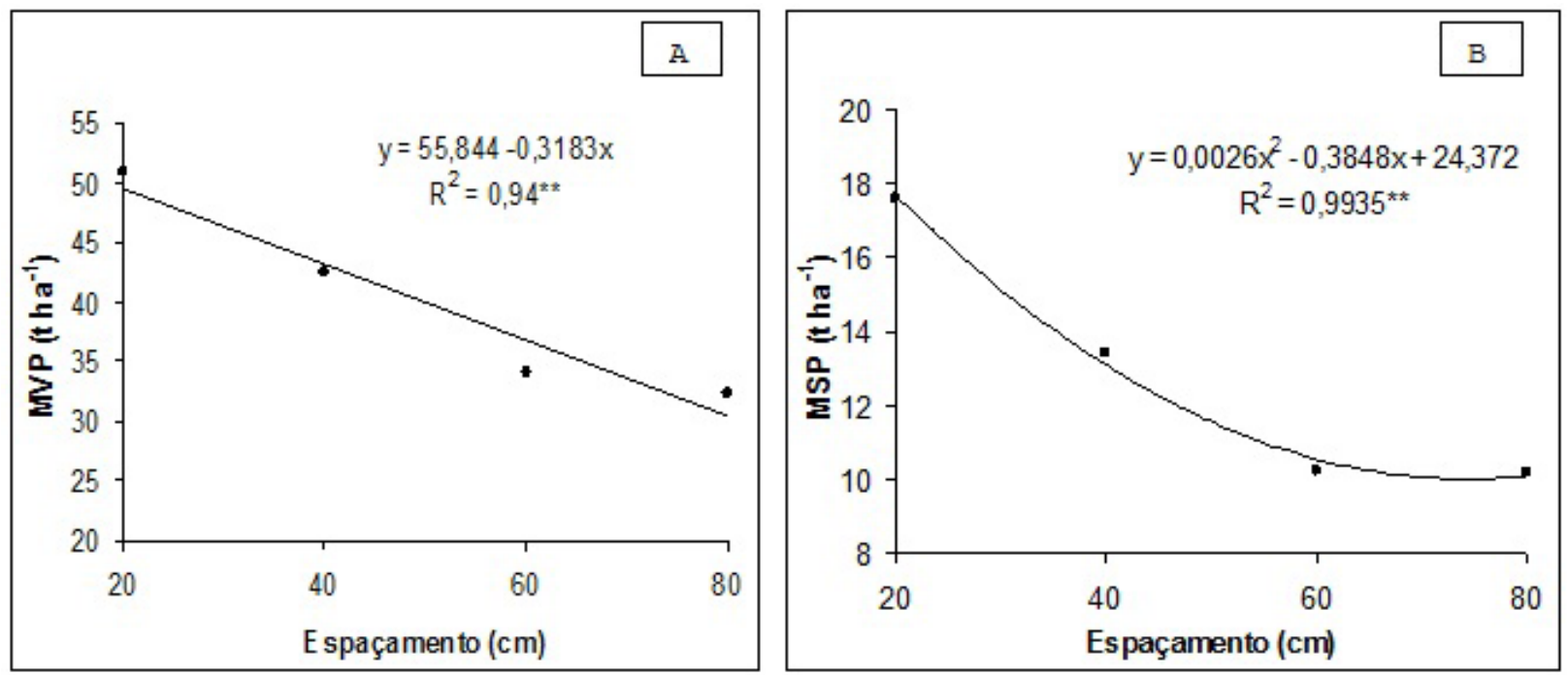

Figura 1. Produção de massa verde (A) e massa seca (B) no estádio de grão pastoso (MVP e MSP) em duas cultivares de milheto, em função do espaçamento entre linhas. Marechal Cândido Rondon-PR. 2008.

O aumento do espaçamento entre linhas e a mesma densidade de semeadura faz com que as plantas fiquem muito próximas umas das outras dentro da linha de semeadura, aumentando assim a competição por água, luz e nutrientes entre as plantas na linha de semeadura, o que provavelmente contribui para a redução da produção de biomassa. Devido a este comportamento, Netto (1998) e Pereira 
Filho et al. (2003) mencionam que quando a cultura do milheto for cultivada objetivando a produção de forragem, o espaçamento entre linhas deve ficar em torno de 30 a $40 \mathrm{~cm}$, onde nestas condições obtém-se maiores rendimentos de biomassa. Salton, Pitol e Erbes (1993) afirmam que para este fim o espaçamento entre linhas deverá ser de 15 a 35 $\mathrm{cm}$. Evidenciando assim que a diminuição do espaçamento entre linhas na cultura do milheto leva ao aumento de potencial de produção de biomassa.

Em relação ao efeito do espaçamento na produção de massa seca no estádio de grão pastoso (MSP) observou-se uma resposta polinomial quadrática. Conforme se aumentou o espaçamento entre as linhas da cultura, ocorreu uma diminuição da massa seca neste estádio, sendo a produção máxima de 17,60 $\mathrm{t} \mathrm{ha}^{-1}$ no espaçamento de 0,20 $\mathrm{m}$ e a produção mínima com 10,19 ton $\mathrm{ha}^{-1}$ no espaçamento de $0,80 \mathrm{~m}$ (Figura $1 \mathrm{~b}$ ). Os resultados obtidos neste trabalho, também estão de acordo aos observados por Codagnone e Sá (1985) que obtiveram produção entre 9 e $21 \mathrm{t} \mathrm{ha}^{-1}$ de massa seca para silagem. Observa-se que a redução da produção foi acentuada do espaçamento de 20 para 60 e que de 60 para 80 esta redução na produção foi menor. Observa-se que em um primeiro momento, isto é, em um determinado intervalo em que se reduz o espaçamento há uma redução de $0,3848 \mathrm{t}$ $\mathrm{ha}^{-1}$ de biomassa seca e no segundo momento esta redução é de apenas $0,0026 \mathrm{t} \mathrm{ha}^{-1}$ de biomassa seca.
Estes dados evidenciam que há uma redução mais drástica na produção de biomassa quando se passa do espaçamento de $20 \mathrm{~cm}$ para $60 \mathrm{~cm}$ do que quando se passa de $60 \mathrm{~cm}$ para $80 \mathrm{~cm}$. Esse comportamento também foi verificado por Silva et al. (2004) e Pawel et al. (1995) que obtiveram a maior produção de massa seca em um menor espaçamento e tiveram a produção reduzida de acordo com o aumento do espaçamento entre as linhas da cultura.

Em relação ao efeito do espaçamento na produção de massa verde no estádio de maturação fisiológica (MVF), houve uma resposta polinomial quadrática, ocorrendo uma diminuição da massa verde neste estádio conforme se aumenta o espaçamento entre as linhas da cultura (Figura 2a), sendo a produção máxima de $57,58 \mathrm{t} \mathrm{ha}^{-1}$ no espaçamento de 0,20 $\mathrm{m}$ e a produção mínima com 35,16 ton $\mathrm{ha}^{-1}$ no espaçamento de $0,80 \mathrm{~m}$, com uma diferença de $22,43 \mathrm{t} \mathrm{ha}^{-1}$ de biomassa fresca quando se passa do espaçamento de 0,20 para 0,80 dando uma redução de aproximadamente $0,2803 \mathrm{t} \mathrm{ha}^{-1}$ a cada um centímetro de aumento no espaçamento. A redução na produção de biomassa verde foi maior entre os espaçamentos de $20 \mathrm{~cm}$ para $60 \mathrm{~cm}$, e comparando a perda de biomassa verde em estádio de grão pastoso com o estádio de maturação observa-se pelas equações estimadas que o decréscimo da biomassa verde em relação ao espaçamento é maior no estádio de grãos pastosos. 

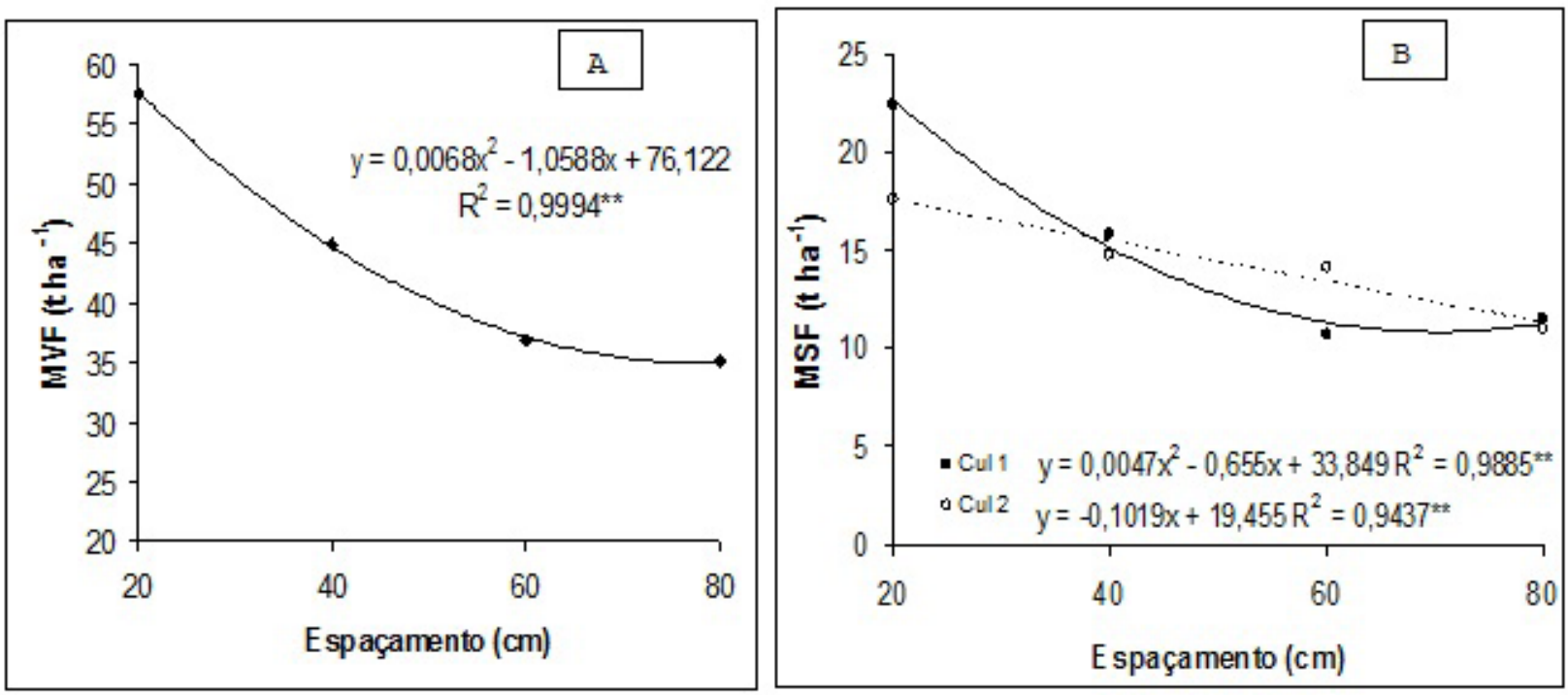

Figura 2. Produção de massa verde (A) e massa seca (B) no estádio de maturação fisiológica (MVF e MSF) em duas cultivares de milheto, em função do espaçamento entre linhas. Cv.1: Comum; Cv.2: IPA-BULK 1. Marechal Cândido Rondon-PR. 2008.

Pawel et al. (1995) avaliando o rendimento de biomassa em função de diferentes espaçamentos, observaram, na maturação, que o rendimento mais elevado de massa verde (44 $\mathrm{t} \mathrm{ha}^{-1}$ ) foi obtido no espaçamento de $15 \mathrm{~cm}$, enquanto nos demais, $40 \mathrm{e}$ $80 \mathrm{~cm}$, a produção declinou. Salton, Pitol e Erbes (1993), Netto (1998) e Pereira Filho et al. (2003) mencionam que quando a cultura do milheto for cultivada objetivando a produção de palhada para cobertura do solo, para o plantio direto, o espaçamento entre linhas deve ficar em torno de 15 a $25 \mathrm{~cm}$, onde nestas condições obtêm-se maiores rendimentos de biomassa.

Como para a variável biomassa seca da parte aérea no estádio de maturação houve interação entre os fatores avaliados, foi realizada analise separadamente para cada cultivar (Figura 2B). A curva que ajustou melhor os pontos para a cultivar Comum foi a polinomial quadrática, comportamento este observado nos dados médios de biomassa seca das cultivares no estádio de grão pastoso. Já os dados obtidos para a cultivar IPA-BULK 1 apresentaram um comportamento linear decrescente de biomassa seca em relação ao aumento do espaçamento. Pelo ângulo beta da equação, observa-se que houve uma diminuição de $0,1019 \mathrm{t} \mathrm{ha}^{-1}$ de matéria seca a medida em que se aumentou o espaçamento. Já para a cultivar Comum esta redução foi de 0,655 $\mathrm{t}$ ha ${ }^{-1}$ em um primeiro momento e de $0,0047 \mathrm{t} \mathrm{ha}^{-1}$ em outro, e a redução foi mais acentuada quando se passou de 20 para $40 \mathrm{~cm}$. Este comportamento pode ser observado também nas curvas apresentadas nas figuras $1 \mathrm{~A}, 1 \mathrm{~B}$ e $2 \mathrm{~A}$.

A produção máxima de biomassa seca colhida no estádio de maturação para a cultivar Comum foi de $22,39 \mathrm{t} \mathrm{ha}^{-1}$ no espaçamento de $20 \mathrm{~cm}$ e a mínima com $11,48 \mathrm{t} \mathrm{ha}^{-1}$ no espaçamento de $80 \mathrm{~cm}$, enquanto que para a cultivar IPA-BULK 1 a produção máxima foi de $17,58 \mathrm{tha}^{-1}$ para o espaçamento de $20 \mathrm{~cm}$ e de $10,97 \mathrm{t} \mathrm{ha}^{-1}$ para o espaçamento de $80 \mathrm{~cm}$.

A produção média de biomassa seca no estádio de maturação obtida, independente da cultivar, foi de $19,98 \mathrm{t} \mathrm{ha}^{-1}$ para o espaçamento de $20 \mathrm{~cm}$ e de $11,22 \mathrm{t} \mathrm{ha}^{-1}$ para o espaçamento de $80 \mathrm{~cm}$, mostrando assim que houve um significativo aumento na produção de biomassa do milheto quando se utiliza o espaçamento de $20 \mathrm{~cm}$, como já citado por vários autores (NETTO, 1998; BONAMIGO, 1999; PEREIRA FILHO et al., 2003).

Geraldo et al. (2002) concluíram que massa seca 
para forragem ou silagem, ainda com alto teor de $\mathrm{N}$ nas folhas, pode ser obtida colhendo o milheto no estádio de maturação fisiológica, podendo ainda utilizar-se da produção de grãos. A massa seca gerada no estádio de maturação fisiológica pode apresentar teores acima dos 7\% de proteína bruta, o que torna uma alternativa para alimentação animal mesmo no final do seu ciclo (YOUNGQUIST; CARTER; CLEGG, 1990).

Como também foi observado interação entre cultivar x espaçamento para a variável produção de grãos, foi relacionado separadamente, por cultivar, a produção de grãos em relação aos espaçamentos utilizados (Figura 3).
Para a cv. Comum observou-se uma resposta polinomial quadrática, ocorrendo uma diminuição da produção de grãos conforme aumenta-se o espaçamento entre as linhas da cultura. A produção máxima de $2306 \mathrm{~kg} \mathrm{ha}^{-1}$ foi obtida no espaçamento de $0,20 \mathrm{~m}$ e a produção mínima com $797 \mathrm{~kg} \mathrm{ha}^{-1}$ no espaçamento de $0,80 \mathrm{~m}$, sendo a redução mais drástica quando se passou do espaçamento de $20 \mathrm{~cm}$ para $40 \mathrm{~cm}$ (Figura 3A). Já em relação a cv. IPABULK 1 , não foi observado um modelo que descrevesse de forma significativa o comportamento deste cultivar. Assim, pode-se dizer que o espaçamento entre linhas não interferiu na produção de grãos, tendo em média uma produção de $1193 \mathrm{~kg} \mathrm{ha} \mathrm{k}^{-1}$ (Figura 3A).
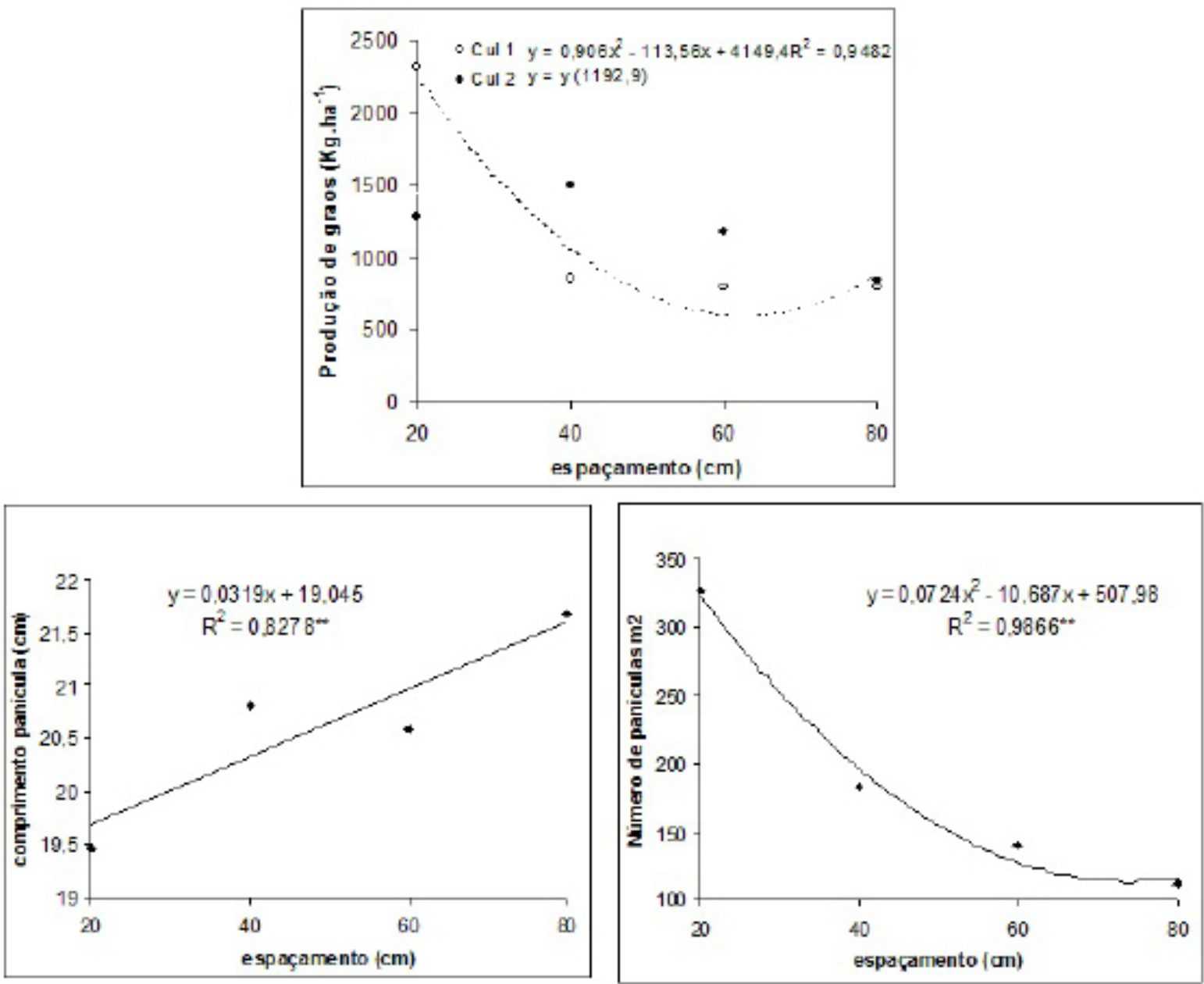

Figura 3. Produção de grãos (PG), Comprimento médio das panículas (CPA) e Número de panículas por metro quadrado (NPA) de duas cultivares de milheto, em função do espaçamento entre linhas. Cv 1: Comum; Cv 2: IPABULK 1. Marechal Cândido Rondon-PR. 2008. 
Os resultados de produção de grãos foram inferiores aos observados por Costa et al. (2005) que obteve produção de $3.232 \mathrm{~kg} \mathrm{ha}^{-1}$ de grãos e também por Geraldo et al. (2002), que observaram rendimentos de até $2.950 \mathrm{~kg} \mathrm{ha}^{-1}$ de grãos. É válido ressaltar que os genótipos utilizados por esses autores apresentavam alto potencial produtivo de grãos. A baixa produção de grãos pode ser atribuída à própria característica genética das cultivares utilizadas neste trabalho, uma vez que estas apresentam aptidão para produção de massa para cobertura do solo e para produção de forragem (NETTO, 1998), além de não ser realizada a adubação. No entanto, a produção de grãos obtida neste trabalho está de acordo com a média brasileira que é de 500 a $1500 \mathrm{~kg} \mathrm{ha}^{-1}$ de grãos (MOREIRA et al., 2003).

Quanto a interferência do espaçamento na produtividade de grãos na cultura do milheto Pereira Filho et al. (2003) mencionam que quando a cultura do milheto for cultivada objetivando a produção de grão, o espaçamento entre linhas deve ficar em torno de 70 a $80 \mathrm{~cm}$, onde nestas condições obtêmse maiores rendimentos de grãos. Scaléa (1999) diz que para este fim, o espaçamento entre linhas a ser adotado deve ser de $40 \mathrm{~cm}$. No entanto, os resultados obtidos neste trabalho contrariam esses autores.

Quanto a relação entre o espaçamento e comprimento da panícula (CPA), observa-se pela Figura 3B que houve um efeito linear e positivo. $\mathrm{O}$ aumento do espaçamento entre linhas proporcionou o maior crescimento das panículas do milheto. Os valores encontrados foram de $19,48 \mathrm{~cm}$ para o espaçamento de $0,20 \mathrm{~m}$ e de $21,68 \mathrm{~cm}$ para o espaçamento de $0,80 \mathrm{~m}$ (Figura 3b). Esses valores estão de acordo com Netto e Durães (2005), que citam que o comprimento médio de panícula de milheto situa-se entre 15 e $45 \mathrm{~cm}$. Silva et al. (2003) observaram que o arranjo populacional de plantas de milheto não teve influência nesta característica. Por outro lado, Costa et al. (2005) citam que o comprimento médio de panícula tem correlação positiva com a produção de grãos.
Em relação ao efeito do espaçamento no número de panículas (NPA), houve uma resposta polinomial quadrática, ocorrendo uma diminuição do NPA conforme aumenta o espaçamento entre as linhas da cultura, sendo a produção máxima de 327 panículas $\mathrm{m}^{-2}$ no espaçamento de $0,20 \mathrm{~m}$ e a produção mínima com 112 panículas $\mathrm{m}^{2}$ no espaçamento de $0,80 \mathrm{~m}$ (Figura 3c). A diferença de panícula por metro quadrado entre os espaçamentos de 20 e $80 \mathrm{~cm}$ foi de 215 panículas $\mathrm{m}^{2}$, mostrando que apesar do aumento do comprimento da panícula observado no espaçamento de $80 \mathrm{~cm}$ e número de panícula por metro quadrado foi bem menor do que no espaçamento de $20 \mathrm{~cm}$. Costa et al. (2005) citam que esta característica tem correlação positiva com a produção de grãos, ou seja, quanto maior o número de panículas maior será a produção de grãos. Isto explica, em parte, o rendimento de grãos obtido no espaçamento de 0,20 m entre linhas. Essa diminuição no número de panículas nos espaçamentos maiores, provavelmente se deve ao arranjo espacial das plantas na parcela, já que há maior competição por água, luz e nutrientes na linha de semeadura conforme o aumento do espaçamento entre as linhas.

\section{Conclusões}

1. O espaçamento entre linhas influenciou significativamente na produção de biomassa verde, biomassa seca e grãos. As maiores produções foram obtidas no espaçamento de $20 \mathrm{~cm}$ entre linhas.

2. As cultivares avaliadas apresentaram elevada produção de biomassa verde, biomassa seca e produtividade de grãos, podendo ser utilizadas na cobertura do solo, alimentação animal na forma de silagem ou para pastejo direto.

\section{Referências}

BONAMIGO, L. A. A cultura do milheto no Brasil, implantação e desenvolvimento no cerrado. In: WORKSHOP INTERNACIONAL DE MILHETO, 1., 1999, Planaltina. Anais... Planaltina: Embrapa Cerrados, 
1999. p. 31-65.

CALEGARI, A.; PEÑALVA, M. Abonos verdes: importância agroecologica y espécies com potencial de uso em El Uruguay. Conelones: Convenio Ministerio de Ganadeira Agricultura y Pesca Del Uruguai (JUNAGRA); Alemanha: Gesellschaft fu Technische Zusammernarbett, 1994. $172 \mathrm{p}$.

CODAGNONE, H. C. V.; SÁ, J. P. G. Avaliação de variedades e híbridos de milho, sorgo e milheto em quatro idades diferentes para produção de silagem ou rolão. Londrina: IAPAR, 1985. 11 p. (IAPAR. Informe Pesquisa, 64).

COSTA, A. C. T. da; GERALDO, J.; PEREIRA, M. B.; PIMENTEL, C. Unidades térmicas e produtividade em genótipos de milheto semeados em duas épocas. Pesquisa Agropecuária Brasileira, Brasília, v. 40, n. 12, p. 1171-1177, dez. 2005.

EMPRESA BRASILEIRA DE PESQUISA AGROPECUÁRIA - EMBRAPA. Sistema brasileiro de classificação de solos. Brasília Brasília: Embrapa-SPI, Embrapa-CNPS, 1999. 412 p.

FIORIN, J. E. Plantas recuperadoras da fertilidade do solo. In: . Curso sobre aspectos básicos de fertilidade e microbiologia do solo em plantio direto: resumos de palestras. Passo Fundo: Aldeia Norte, 1999. p. $39-55$.

GERALDO, J.; OLIVEIRA, L. D. de; PEREIRA, M. B.; PIMENTEL, C. Fenologia e produção de massa seca e de grãos em cultivares de milheto pérola. Pesquisa Agropecuária Brasileira, Brasília, v. 37, n. 9, p. 12631268, set. 2002.

KICHEL, A. N.; MIRANDA, C. H. B. Uso do milheto como planta forrageira. Campo Grande: Embrapa Gado de Corte, 2000. (Embrapa Gado de Corte. Gado de Corte Divulga, 46).

LANDERS, J. N. A safrinha. In: Fascículo de experiências de plantio direto no cerrado. Goiânia: Associação de Planto Direto no Cerrado, 1994. cap. 4, p. 53-88.

MAGGI, A. B. Efeitos da competição de plantas daninhas em cultivares de feijão (Phaseolus vulgaris). Planta Daninha, Viçosa, v. 3, n. 2, p. 105-154, 1994.

MORAES, A. de; MARASCHIN, G. E. Pressões de pastejo e produção animal em milheto cv. comum. Pesquisa Agropecuária Brasileira, Brasília, v. 23, n. 2, p. 197-205, 1988.

MOREIRA, L. B.; MALHEIROS, M. G.; CRUZ, B. B. G. da; ALVES, R. E. de A.; OlIVEIRA, K. R. S. de. Efeitos da população de plantas sobre as características morfológicas e agronômicas de milheto pérola (Pennisetum glaucum (L.) R. Brown) cv. ENA 1. Agronomia, Seropédica, v. 37, n. 1, p. 5-9, 2003.

NETTO, D. A. M. A cultura do milheto. Sete Lagoas: Embrapa-CPMS, 1998. 6 p.

NETTO, D. A. M.; DURÃES, F. O. M. Milheto: tecnologias de produção a agronegócio. Brasília: EMBRAPA Informação Tecnológica, 2005. 215 p.

PAWEL, J. W.; DAVID, L. W.; WAYNE, H.; JERZY, A. P.; JAN, S.; TEARE, I. D. Plant populations and seeding rates. In: NATIONAL GRAIN PEARL MILLET, 1., 1995, Tifton. Proceedings.... Tifton: University of Geórgia, 1995. p. 32-37.

PEREIRA FILHO, I. A.; FERREIRA, A. da S.; COELHO, A. M.; CASELA, C. R.; KARAM, D.; RODRIGUES, J. A. S.; CRUZ, J. C.; WAQUIL, J. M. Manejo da cultura do milheto. Sete Lagoas: Embrapa Milho e Sorgo, 2003. 65 p. (Embrapa Milho e Sorgo. Circular Tecnica, 29).

SALTON, J. C.; PITOL, C.; ERBES, E. J. Cultivos de primavera: alternativas para produção de palha em Mato Grosso do Sul. Maracaju: Fundação MS, 1993. 6 p. (Fundação MS. Informativo Técnico, 1).

SCALÉA, M. A cultura do milheto e seu uso no plantio direto no cerrado. In: WORKSHOP INTERNACIONAL DE MILHETO, 1., 1999, Planaltina. Anais... Planaltina: Embrapa Cerrados, 1999. p. 75-83.

SILVA, N. B. da; SILVA, A. C. da; COSTA, A. C. T. da; PIMENTEL, C. Efeito da população de plantas na produção de biomassa e de grãos de milheto pérola, "cultivar ENA 1", semeando na época seca. Revista Universidade Rural, Série Ciência e Vida, Seropédica, v. 24, n. 1, p. 57-62, jan./jun. 2004.

SILVA, G. F.; ERASMO, E. A. L.; SARMENTO, R. de A.; SANTOS, A. R. dos; AGUIAR, R. W. de S. Potencial de produção de biomassa e matéria seca de milheto (Pennisetum americanum SChum.), em diferentes épocas no sul do Tocantis. Bioscience Journal, Uberlândia, v. 19, n. 3, p. 31-34, 2003.

WANG, J.; HESKETH, J. D.; WOOLLEY, J. T. Preexisting channels and soybean rooting patterns. Soil Science, Philadelphia, v. 141, n. 6, p. 432-437, 1986.

YOUNGQUIST, J. B.; CARTER, D. C.; CLEGG, M. D. Grain and forage yield and stover quality of sorghum and millet in low rainfall environments. Experimental Agriculture, London, v. 26, n. 3, p. 279-286, 1990. 